\title{
Modelo Conceitual para Planejamento e Gestão de Programas Turísticos e Recreativos em Áreas Naturais
}

\author{
A Conceptual Model for the Planning and Management of \\ Tourism and Recreation Programmes in Natural Areas
}

\section{Regiane Vilas Bôas'}

\begin{abstract}
RESUMO: Um modelo conceitual é desenvolvido nesse artigo com a finalidade de levar informações sobre planejamento turístico e recreativo e estimular decisões de grupos técnicos que trabalham com esse tema. Serão discutidos alguns componentes importantes do planejamento participativo de maneira a fornecer uma melhor visão da relação entre o ambiente natural, atividades de turismo/recreação, ecoturistas e comunidade local. Portanto, este artigo concentra a discussão de temas relacionados ao planejamento participativo de atividades turísticas e recreativas e ao manejo de áreas naturais, em que engenheiros florestais, turismólogos, planejadores, diretores e outros possam trabalhar em planos de gestão e conservação de forma a não interferir abruptamente no ambiente, tornar a experiência dos ecoturistas mais proveitosa, maximizar os benefícios econômicos e promover uma larga interação da comunidade local com os aspectos sociais e culturais.
\end{abstract}

PALAVRAS-CHAVE: planejamento turístico; planejamento participativo; programas turísticos e recreativos; áreas naturais; modelo conceitual.

ABSTRACT: A conceptual model is developed herein for the purpose of stimulating discussions with groups planning and carrying out information about integrated tourism planning. It will be described components of

1. Bacharel em Engenharia Florestal e mestre em Manejo Ambiental pela Universidade Federal de Lavras - UFLA; especialista em Turismo pela Wageningen University - WAU, Holanda. É aluna estagiária na WAU, onde integra o Grupo de Análise Socioespacial do Uso do Solo (Recreação e Turismo), no Departamento de Ciências Ambientais. Contato: Universidade Federal de Lavras (Departamento de Ciências Florestais), CP 37 - 37200-000 - Lavras - MG; e-mail: regiane@ufla.br. 
participatory planning in way provide one better view of the relationship between the utilization of the natural environment, recreation and tourism activities, visitors and local community. The focus of this paper is on participatory planning in tourism management developed in contacted with natural resources, where foresters, planners, managers, and others come together to work on conservation plans, management plans, or other multidisciplinary environmental analyses in a way to not interfere abruptly in the environment, to turn the visitor's experience more enjoyable and profitable, to maximize economic benefits to the local community and to promote an larger integration of their with cultural/social aspects.

KEYWORDS: touristic planning; participatory planning; touristic and recreational programs; natural areas; conceptual model.

\section{Introdução}

Imagine-se a seguinte situação: uma determinada área natural, com poten cial turístico e um grande número de ecoturistas, cuja visitação ocorre apenas em pontos estratégicos e sem o acompanhamento de guias. Neste caso, a pressão do uso sobre os recursos e a ausência de um planejamento efetivo e de um correto manejo dessa área podem colocar em risco os recursos naturais que atraem os ecoturistas. Como resultado, áreas com potencial turístico como Kenya, Galapos e Tailândia têm sido profundamente impactadas (Boyd e Butler, 1996).

Portanto, esse tipo de exploração turística pode gerar impactos significativos e de ampla dimensão, além de poder provocar transformações ecológica e culturalmente expressivas, afetando a vegetação, o solo, a água, a fauna, os recursos históricos e culturais e, principalmente, as experiências dos visitantes. Neste caso, faz-se necessário o trabalho de um grupo técnico interdisciplinar visando o planejamento e o manejo adequados desta área, o que coloca para esse grupo uma importante questão: como promover o turismo e a recreação em uma área natural, oferecendo aos visitantes experiências e oportunidades de lazer e, ao mesmo tempo, garantir a conservação do local?

A regra geral é que zonas propícias ao desenvolvimento de atividades turísticas e recreacionais requerem planejamento participativo, um processo através do qual o grupo técnico (engenheiros florestais, turismólogos, ecologistas, biólogos, diretores, etc.) poderá criar alternativas para otimizar os resultados do turismo.

Portanto, este artigo tem como objetivo propor um modelo conceitual a ser utilizado em planejamento turístico e recreativo que envolva recursos naturais. O conceito global proposto não é novo, mas baseado em literatura existente e já implementada no campo de planejamento e manejo de recursos naturais, incorporando as idéias de Recreational Opportunity Spectrum (ROS) e Tourism Opportunity Spectrum (TOS), ambas apresentadas por Clark e Stankey (1979) e amplamente empregadas em áreas naturais com potencial turístico. Além disso, o modelo proposto também foi derivado de outros estudos, como os de Weaver e Lawton (2001) e Boyd e Butler (1996).

\section{Participação: base para o planejamento turístico e recreativo}

O modelo conceitual de planejamento turístico e recreativo traz como discussão central a questão da participação.

A participação pode ser vista como um direito humano (Fao Apud Shetty, 1991), como um meio autônomo de opinar ou como a habilidade de grupos de indivíduos de influenciar a direção e os resultados do desenvolvimento de programas que afetarão os próprios participantes.

Na opinião de Alencar e Gomes (2001), o ideal é que a intervenção ${ }^{2}$ assuma um caráter educativo, pois a população-alvo é estimulada pelo agente externo a desenvolver a habilidade de diagnosticar e analisar seus problemas, decidir coletivamente sobre as ações para solucioná-los, executar tais ações e avaliá-las, buscando, sempre que necessário, novas alternativas. Na abordagem participativa, o agente externo deve ter um papel educativo e sua função deve se fundamentar no método pedagógico conhecido por "conscientização", elaborado por Paulo Freire, cujo elemento central é a "reflexão-ação".

Observa-se que antigamente, em muitas comunidades rurais, poucos habitantes participavam do melhoramento das condições locais. Mais recentemente, alguns deles passaram a tomar a iniciativa de apresentar reivindicações ao poder público, ao mesmo tempo em que tomavam parte em ações locais de melhoria. Após avaliar sua situação, encaminhavam às autoridades queixas e demandas de serviços de água, esgoto, transporte, segurança, saúde, etc. Hoje essas comunidades já ganharam influência e capacidade de intervenção em áreas de decisão antes zelosamente monopolizadas pelas prefeituras, passando de uma participação de

2. Intervenção pode ser entendida como uma ação ou um conjunto de ações praticadas por pessoas (extencionistas, técnicos, etc.) que não pertencem ao núcleo comunitário onde tal experiência se realiza. Tais pessoas serão aqui denominadas de agentes externos. O processo de intervenção pode assumir um caráter convencional/tutorial ou participativo/educativo (Alencar e Gomes, 2001). 
níveis 3 e 6 para uma participação de níveis 3 e 4 . Além disso, algumas ONGs, fundamentadas nas obras de Paulo Freire, já vinham desenvolvendo metodologias de intervenção centradas na participação dos pequenos produtores na formulação e implementação de projetos de desenvolvimento. No final da década de 1970, a "participação" também foi incorporada aos programas financiados por instituições como Banco Mundial, FAO, Organização Mundial do Trabalho, Organização Mundial da Saúde e por organismos locais nas estratégias de intervenção de diversos países (Alencar; Gomes, 2001). Atualmente, levantamentos realizados com base na comunidade local e nos turistas têm sido amplamente conduzidos em áreas naturais na Malásia (Chin et al., 2000), Canadá (Saleh e Karwachi, 1996), Nova Zelândia (Balcar e Pearce, 1996), Uganda (Obua e Harding, 1996) e Austrália (Ryan e Sterling, 2001; Morgan, 2000 e Lok, 2000). Gunn (1993) e Murphy (1985) estão entre os pesquisadores que enfatizam a importância do planejamento participativo.

\section{Planejamento Turístico e Recreativo: elaboração de diretrizes}

O plano é uma ferramenta que reúne informações com a finalidade de facilitar a tomada de decisão e implementar diretrizes, é um documento que geralmente articula sua intenção após ter sido objeto de consulta e debate público. Para tanto, existem parâmetros de contextualização relevantes, capazes de solucionar ou contornar problemas humanos.

Nesse sentido, Bettelini, Cantini e Mariotta (2000) e Alencar e Gomes (2001) afirmam que existem três níveis de análise: micro (características do mundo próximo), meso (características do mundo relativamente próximo) e macro (características do mundo mais distante). Tais parâmetros podem ampliar a capacidade de reflexão - tanto do agente externo quanto do grupo com o qual ele trabalha -, sobre os problemas pertinentes às suas atividades cotidianas e às oportunidades que o meio ambiente lhes oferece. Além disso, acredita-se que o planejamento não é uma disciplina isolada, mas uma combinação de muitas outras (Gunn, 1993). O planejamento deve englobar fatores sociais, econômicos, políticos, antropológicos, ambientais e técnicos; deve ter relação com o passado, o presente e o futuro. Todavia, os participantes devem ter um desejo verdadeiro de construir um consenso e buscar soluçōes mutuamente aceitáveis.

3. De acordo com Bordenave (1983), citado por Alencar e Gomes (2001), as decisōes podem ser organizadas em níveis que variam do grau mais alto para o mais baixo: Nível 1: formulação da política da instituição; Nível 2: determinação de objetivos e estabelecimento de estratégias; Nível 3: elaboração de planos, programas e projetos; Nível 4: alocação de recursos e administração de operaçōes; Nível 5: execução de ações; Nível 6: avaliação dos resultados.
Bannon (1976) descreve um esquema essencial, no qual ele inclui o processo de investigação e integração para o planejamento turístico e recreativo visando implementação, avaliação e feedback. Alencar e Gomes (2001), seguindo o modelo enfocado na estratégia de intervenção denominada "educação participativa", afirmam que esse processo envolve quatro subprocessos: o estabelecimento dos objetivos, a identificação dos meios e das condições (obstáculos) e as respostas às questões formuladas, constituindo assim o diagnóstico de realidade. Para Inskeep (1991), o processo básico de planejamento deve seguir alguns outros passos sucessivos: estudos de preparação, determinação de objetivos e ferramentas, levantamentos, análises e sínteses, formulação do plano, recomendações, implementação e monitoramento.

Para Boyd e Butler (1996), o planejamento e o manejo de atividades turísticas e recreativas devem considerar oito fatores importantes ao desenvolvimento do ecoturismo:

1. acessibilidade;

2. relação entre o ecoturismo e demais usos;

3. atrações existentes na região;

4. existência e tipos de infra-estrutura local;

5. nível de habilidade dos usuários e conhecimento requerido;

6. nível de interação social;

7. nível de impacto aceitável e controle necessário;

8. tipo de manejo requerido.

Os sete primeiros fatores podem constituir um conjunto de oportunidades turísticas que abrangerão desde eco-especialistas até eco-generalistas ${ }^{4}$ (Tabela 1).

Além disso, deve-se lembrar que os planos requerem manejo permanente e não terminam apenas quando se finaliza sua elaboração. Precisam envolver monitoramento progressivo, avaliação, descobertas e adaptação. Faz-se necessário, ainda, que o mesmo seja executável dentro de um período de tempo estabelecido (Torkildsen, 1986).

4. Eco-especialistas são ecoturistas que participam do plano individualmente ou em pequenos grupos, interagindo com o ambiente cultural e natural por meio de modesta infra-estrutura a fim de causar impacto ambiental mínimo. Os eco-generalistas, por outro lado, representam grandes grupos, normalmente organizados por agências, exigem um certo nível de conforto e tendem a "consumir" mais intensamente a cultura e o ambiente local. Há também os ecoturistas intermediários, que preferem viajar em pequenos grupos, utilizam formas básicas de transporte e infra-estrutura local e contam com facilidades previamente organizadas (Fernie, 1993). 
Tabela 1: Componentes do espectro ecoturístico

\begin{tabular}{|c|c|c|c|c|}
\hline \multirow[b]{2}{*}{ Componentes } & & \multicolumn{3}{|c|}{ Espectro Ecoturístico } \\
\hline & & Eco-Especialista & Intermediário & Eco-Generalista \\
\hline \multirow[t]{4}{*}{ Acesso } & $\begin{array}{l}\text { Grau de dificuldade } \\
\text { Vias/Terminal }\end{array}$ & $\begin{array}{l}\text { árduo e difícil } \\
\text { água; trilhas }\end{array}$ & $\begin{array}{l}\text { díficil e vigoroso } \\
\text { aeroporto } \\
\text { estradas (pontes } \\
\text { móveis e } \\
\text { de madeira) }\end{array}$ & $\begin{array}{l}\text { moderado e fácil } \\
\text { aeroporto } \\
\text { estradas (pavimentadas) }\end{array}$ \\
\hline & Mercado & experiência pessoal & $\begin{array}{l}\text { turismo } \\
\text { local }\end{array}$ & companhias de viagem \\
\hline & $\begin{array}{l}\text { Canais de } \\
\text { informação }\end{array}$ & boca a boca & $\begin{array}{l}\text { boca a } \\
\text { boca }\end{array}$ & $\begin{array}{l}\text { propaganda (brochuras } \\
\text { de turismo local) } \\
\text { companhias de turismo }\end{array}$ \\
\hline & $\begin{array}{l}\text { Meios de } \\
\text { transporte }\end{array}$ & a pé; canoa; cavalo & $\begin{array}{l}\text { a pé; canoa; } \\
\text { cavalo }\end{array}$ & veículos motorizados \\
\hline $\begin{array}{l}\text { Atividades } \\
\text { relacionadas } \\
\text { aos recursos }\end{array}$ & & incompatível & $\begin{array}{l}\text { dependente da } \\
\text { natureza } \\
\text { e extensão }\end{array}$ & $\begin{array}{c}\text { compatível em grande } \\
\text { escala }\end{array}$ \\
\hline $\begin{array}{l}\text { Atrações } \\
\text { oferecidas }\end{array}$ & & $\begin{array}{l}\text { orientada para o } \\
\text { ambiente natural }\end{array}$ & $\begin{array}{l}\text { orientada para o } \\
\text { ambiente natural }\end{array}$ & $\begin{array}{l}\text { focalizada na cultura e } \\
\text { nos aspectos urbanos }\end{array}$ \\
\hline \multirow[t]{4}{*}{$\begin{array}{l}\text { Infra-estrutura } \\
\text { existente }\end{array}$} & Extensão & não complexa & $\begin{array}{l}\text { desenvolvida } \\
\text { somente em áreas } \\
\text { isoladas }\end{array}$ & $\begin{array}{l}\text { moderadamente } \\
\text { desenvolvida }\end{array}$ \\
\hline & Visibilidade & nenhuma & $\begin{array}{l}\text { primariamente } \\
\text { natural }\end{array}$ & mudanças óbvias \\
\hline & Complexidade & não complexo & $\begin{array}{c}\text { nível de } \\
\text { complexidade } \\
\text { em aumento }\end{array}$ & $\begin{array}{l}\text { nivel de } \\
\text { complexidade } \\
\text { em aumento }\end{array}$ \\
\hline & Facilidades & nenhuma & $\begin{array}{c}\text { procura e resgate } \\
\text { acomodações rústicas } \\
\text { algum conforto (alojam.) }\end{array}$ & $\begin{array}{l}\text { muito conforto } \\
\text { (hotéis e casas) }\end{array}$ \\
\hline \multirow[t]{2}{*}{$\begin{array}{l}\text { Interaçāo } \\
\text { social }\end{array}$} & Outros ecoturistas & $\begin{array}{l}\text { evitam ou têm } \\
\text { pequeno contato }\end{array}$ & $\begin{array}{l}\text { algum contato (passeios } \\
\text { em pequenos grupos) }\end{array}$ & $\begin{array}{l}\text { contato freqüente } \\
\text { (passeios em } \\
\text { grandes grupos) }\end{array}$ \\
\hline & Comunidade local & pequeno contato & $\begin{array}{l}\text { algumas interpretações e } \\
\text { uso de serviços básicos }\end{array}$ & $\begin{array}{l}\text { contato freqüente: } \\
\text { serviços e artesanato }\end{array}$ \\
\hline $\begin{array}{c}\text { Nível de } \\
\text { habilidade e } \\
\text { conhecimento }\end{array}$ & & $\begin{array}{l}\text { profissional e } \\
\text { extensivo }\end{array}$ & extensivo a limitado & $\begin{array}{l}\text { mínimo e sem } \\
\text { conhecimento }\end{array}$ \\
\hline \multirow[t]{2}{*}{$\begin{array}{l}\text { Aceite de } \\
\text { impactos dos } \\
\text { visitantes }\end{array}$} & $\begin{array}{l}\text { Crau de impacto } \\
\text { Prevalência de } \\
\text { impacto }\end{array}$ & $\begin{array}{l}\text { nenhum } \\
\text { mínimo ou } \\
\text { incomum }\end{array}$ & $\begin{array}{l}\text { baixo a moderado } \\
\text { prevalecente em } \\
\text { pequenas áreas }\end{array}$ & $\begin{array}{c}\text { alto } \\
\text { prevalecente }\end{array}$ \\
\hline & Nível de controle $r$ & nenhum controle & controle mínimo & $\begin{array}{l}\text { controle moderado } \\
\text { a estrito }\end{array}$ \\
\hline
\end{tabular}

Fonte: Baseado em Boyd e Butler (1996).

\section{Componentes Básicos do Planejamento Turístico e Recreativo}

A obtenção de informações é indispensável para a condução dos subprocessos diagnóstico, acompanhamento e avaliação (Alencar e Gomes, 2001). No entanto, é impossível responder às questões levantadas nesses subprocessos sem o emprego de métodos ou técnicas de pesquisa. Para tanto, pode-se lançar mão de métodos como: observação (participante e não participante), entrevista, grupo focal, história oral e história de vida, experimento, survey (pesquisa por amostragem) e estudo de caso. Além disso, a combinação de métodos qualitativos e quantitativos em uma mesma pesquisa pode ser utilizada nos acompanhamentos e avaliação de programas e projetos.

\section{Identificação dos participantes: interação social}

Deve-se lembrar que o informante é uma pessoa que pertence ao grupo estudado e se dispõe a revelar aspectos da vida, dos valores, dos costumes, da estrutura social e da história desse grupo, introduzindo o pesquisador no locus do seu estudo. $\mathrm{O}$ uso de informantes, no entanto, requer alguns cuidados.

Primeiramente, não se pode esperar que o informante conheça tudo sobre a vida do grupo ou que esteja disposto a falar sobre tudo aquilo que ele conhece; como qualquer ser humano, ele é seletivo em sua narrativa. Em segundo lugar, as informações por ele transmitidas podem estar sujeitas a distorções em decorrência de seus próprios interesses, simpatias, amizades e interpretações. Frente a essas possíveis limitações, Sudman e Bradburn (1982), citados por Alencar e Gomes (2001), comentam que seria conveniente o uso de múltiplos informantes e o cruzamento de suas informações.

Dessa forma, a integração dos participantes pode ser uma tarefa difícil, mas de crítica importância por razões técnicas, políticas e eventualmente operacionais. Nessa etapa, de acordo com a Figura 1, é necessário examinar a interação entre as comunidades locais - como indivíduos, grupos e instituições - que possam contribuir para o planejamento.

\section{Grupo focal como técnica auxiliar na investigação}

As pessoas obtêm prazer das atividades turísticas e recreativas e, individualmente, reivindicam objetos, locais e experiências autênticas. Portanto, ao iniciar a pesquisa, recomenda-se uma explanação sobre os objetivos do planejamento, o motivo pelo qual o entrevistado foi selecionado, a importância das suas respos- 


\section{Autoridades políticas}

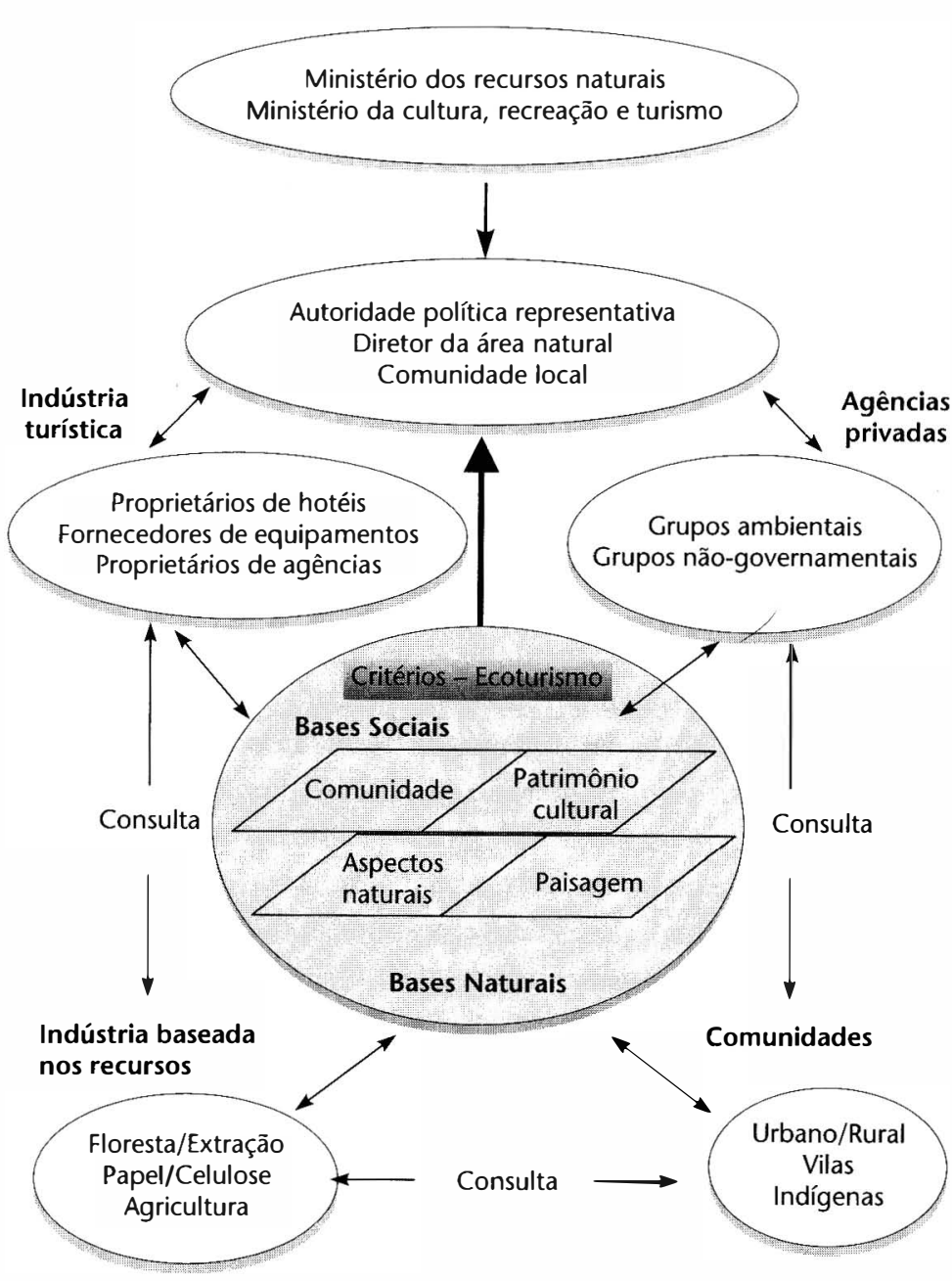

Figura 1. Tomada de decisão e o envolvimento da comunidade

Fonte: Baseado em Boyd e Butler (1996)

tas para o estudo e que elas serão analisadas em conjunto com as respostas de outros entrevistados, preservando-se o anonimato.

Um sistema narrativo poderá auxiliar na busca por informaçōes-chave pertinentes às experiências vividas pelos participantes da pesquisa. Portanto, nessa fase pode-se explorar técnicas de pesquisa como o grupo focal. As discussōes poderão ter duração de uma hora, aproximadamente (Gobster, 1998), e os grupos poderão compreender de cinco a onze participantes (Veal, 1997). Cada grupo poderá ser formado por pessoas das seguintes idades: de 7 a 11 anos, 12 a 19 anos, 20 a 40 anos e acima de 40 anos. A pesquisa poderá, ainda, ser constituída por representantes da zona rural, da zona periférica e da zona central local, além do facilitador e de um anotador. O grupo focal poderá ser conduzido até o ponto de saturação, ou seja, quando se observa o início da repetição das respostas (Straus e Corbin, 1990).

\section{Aplicação de questionários e utilização da técnica da observação}

O manejo bem-sucedido de áreas naturais depende também do conhecimento sobre os ecoturistas e suas características de uso (Morin et al., 1997). Nessa etapa, os visitantes se tornam o centro da pesquisa e é essencial o perfeito conhecimento de seus atributos demográficos, sociográficos e psicográficos (Galloway, 2002). Além disso, deve-se lembrar que as condiçōes de turismo e recreação variam, dependendo da estação, do dia da semana e da hora do dia (Veal, 1997). Portanto, deve-se utilizar uma estratégia de amostragem que capte essas variaçōes.

A busca por informaçōes pode se dar por meio de metodologias como a observação c, nesse caso, pode-se lançar mão de locais de recreação selecionados na área natural. Já o emprego de questionários pode ser efetuado no ponto de chegada ou na saída da área. Os questionários poderão ser preenchidos pelos próprios visitantes e depositados em locais estrategicamente fixados para a coleta. De acordo com Obua e Harding (1996), essa metodologia pode ser utilizada com o propósito de facilitar a coleta de informaçôes, pois se considera que tal expediente garante uma maior liberdade de opinião para os visitantes.

\section{Levantamento da diversidade de recursos e oportunidades}

As características de um local influenciam a existência e o tipo de atividades recreativas. Além disso, locais naturais têm sido apontados como algumas das principais estratégias na conservação ambiental. Nesse sentido, o desenvolvimento de atividades turísticas e recreativas requer estudos adequados a fim de evitar a depreciação dos recursos e de se conhecer o potencial turístico local. Assim, fazem-se necessários levantamentos com foco nos assuntos relacionados aos recursos naturais, à infra-estrutura existente e aos possíveis impactos, além de estudos sobre a biodiversidade e sustentabilidade (Backman, 2001).

Nessa fase, informaçōes importantes ao desenvolvimento das atividades turísticas e recreativas devem ser coletadas, tais como os aspectos do ambiente 
físico (clima, geologia, geomorfologia, relevo, solos e hidrologia), aspectos do ambiente biológico (vegetação e fauna), capacidade de carga e zoneamento.

Além de levantamentos da área, fontes secundárias de dados poderāo ser também empregadas na tentativa de atender aos objetivos propostos, e poderão ser extraídas de publicações, relatórios oficiais, planos de manejo e outras fontes de literatura sobre o local de pesquisa.

\section{Informações relevantes: possiveis fatores de combinações}

Os levantamentos realizados com a comunidade e com ecoturistas devem buscar informações sobre como as pessoas geralmente aproveitam seus momentos de lazer, o que elas gostariam de fazer e o que elas planejam fazer. Essas respostas, de acordo com Veal (1997), podem ser vistas como indicadores de sentimentos, do que as pessoas podem estar planejando fazer em condições favoráveis e quais são as atividades mais populares.

\section{Experiências, necessidades e desejos da comunidade}

Com a finalidade de se obter um maior discernimento com relação às atitudes da comunidade local e avaliar os tipos de experiências desenvolvidas, as questões norteadoras das discussões podem ser elaboradas com base nos objetivos e nos aspectos relevantes ao planejamento, bem como na literatura pertinente ao assunto. Portanto, um quadro com quatro seções foi elaborado (Figura 2) com a finalidade de obterem-se dados relevantes. A seçāo A contém questões relacionadas à percepção da comunidade sobre o local; a seção $\mathrm{B}$ diz respeito ao nível de conhecimento sobre a área; a seção $\mathrm{C}$ relaciona-se aos pontos básicos necessários ao planejamento turístico e recreativo; enquanto a seção $D$ oferece instruçōes que refletem as formas de suporte e manutençāo do plano a ser proposto à área natural.

\section{Visitantes e seus atributos}

A existência de atividades turísticas e recreativas na área possibilita a coleta de informações detalhadas sobre os ecoturistas, pois a escolha da oportunidade pelo visitante (ou a preferência expressada) fornece feedback sobre a preferência.
Assim, o questionário poderá compreender as quatro seções, cada uma abrangendo diferentes assuntos: perfil socioeconômico e cultural dos ecoturistas; análise da visitação e comportamento; caracterização das percepções dos ecoturistas e assuntos relacionados ao manejo da área. Dessa forma, os ecoturistas têm a possibilidade de participar de diferentes tipos de atividades derivando daí, portanto, satisfação e experiências. A intenção é descrever sistematicamente um modelo (Figura 3) que permita a coleta de informações capazes de fornecer bases para o planejamento de oportunidades diversificadas.

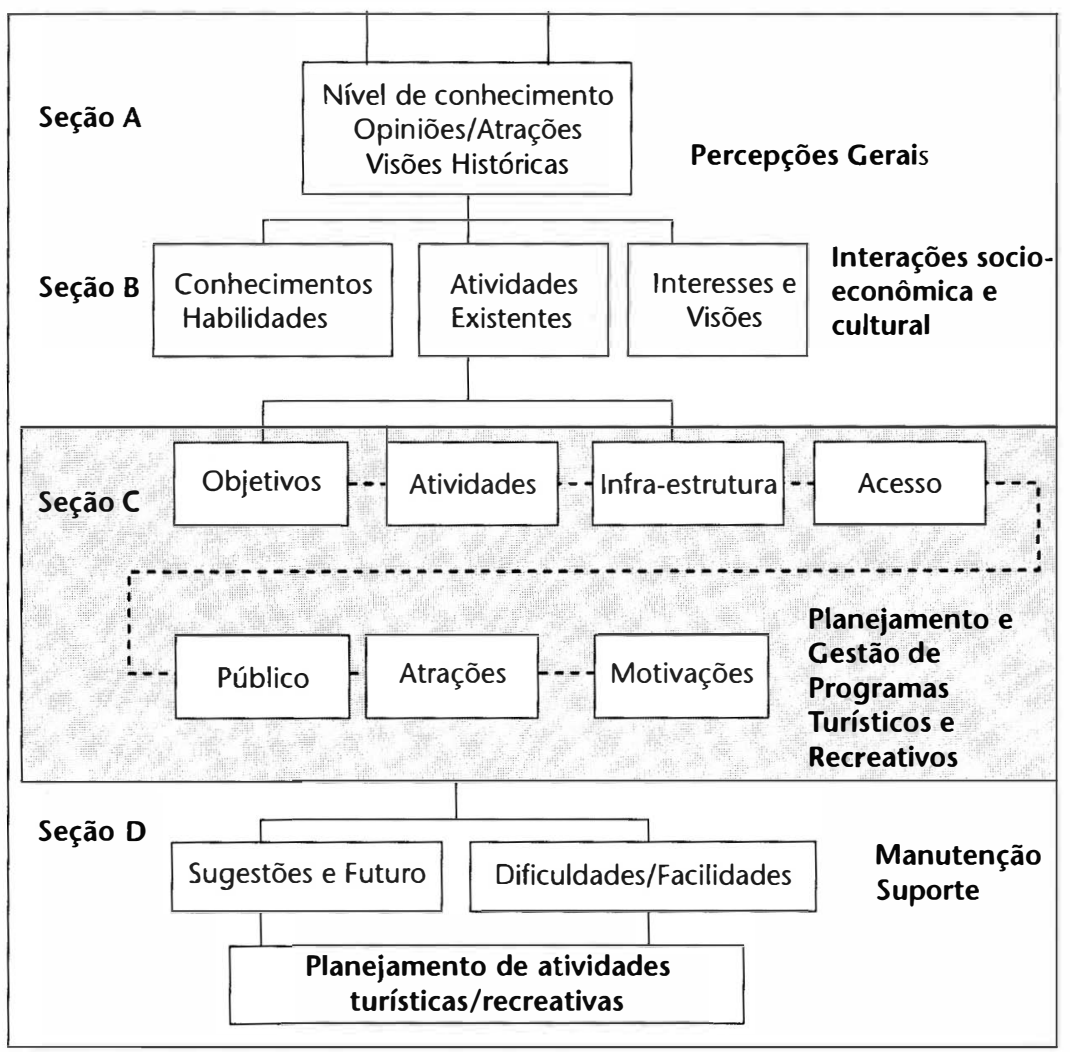

Figura 2. Informações úteis ao planejamento participativo, capazes de gerar interação, design e gestão

Fonte: Baseado em Bissix (2000). 


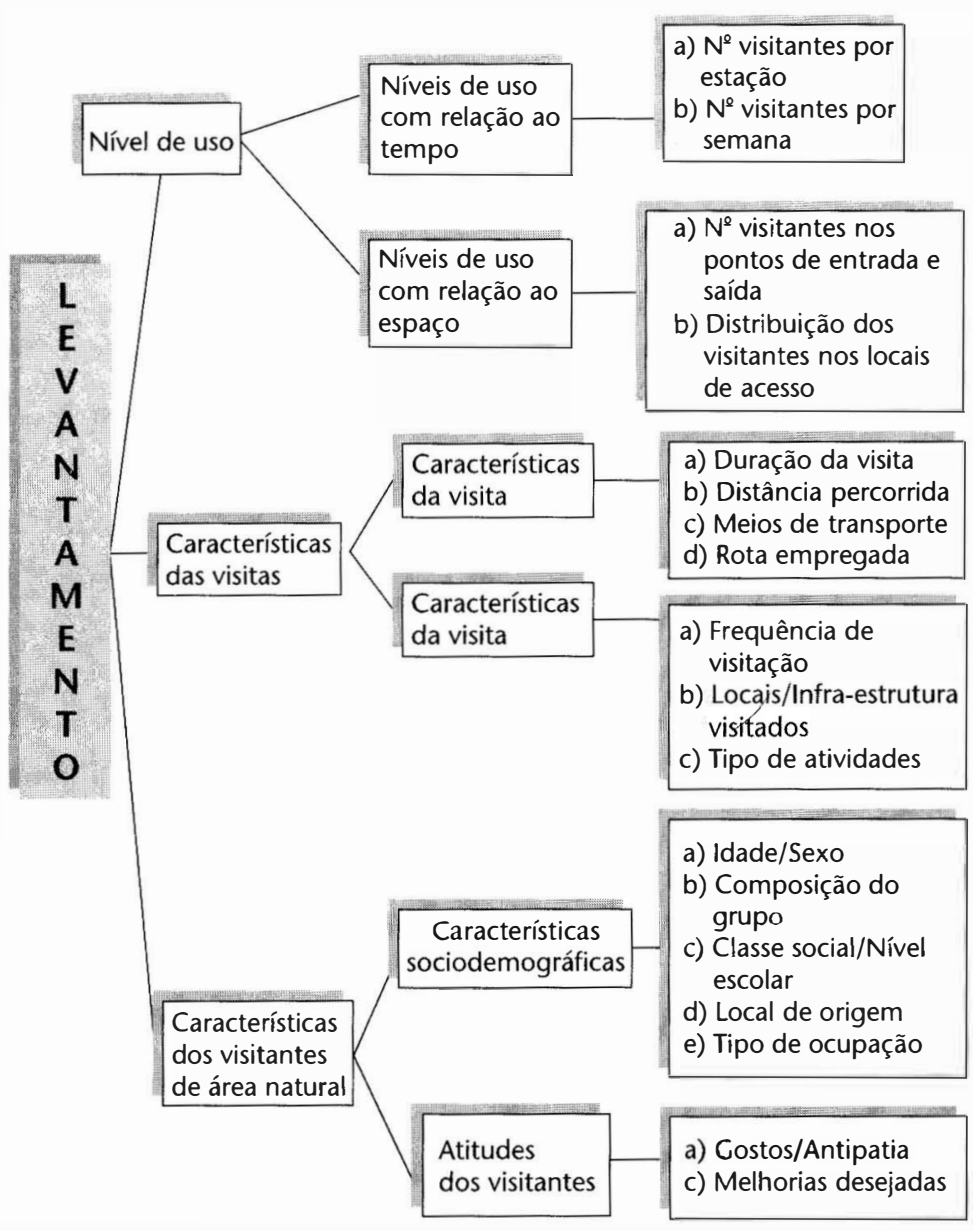

Figura 3. Informações úteis sobre os visitantes da área natural

Fonte: Baseado em Spon (1983).

\section{Conclusão}

O turismo é um assunto amplo e complexo, e o envolvimento da comunidade local e dos ecoturistas no planejamento tem sido visto como um pré-requisito para o turismo sustentável. Portanto, o artigo procurou discutir um modelo conceitual com vistas a assistir pesquisadores e diretores de áreas naturais. As idéias aqui discutidas buscaram encorajar a análise da participação, examinar o planejamento participativo e envolver o aprendizado coletivo e a construção de consenso. O desenvolvimento do turismo sem a integração dos valores locais pode trazer danos sociais, culturais, ambientais e econômicos.

Assim, ao empregar conceitos como Tourism Opportunity Spectrum (TOS) e Recreation Opportunity Spectrum (ROS), demonstrou-se ser possível oferecer um conjunto de alternativas turísticas e recreativas que podem possibilitar uma variedade de experiências. No entanto, o modelo apresentado é um processo conceitual e, enquanto tal, requer aplicação por parte dos diretores de áreas naturais que, por sua vez, por meio de suas próprias experiências, poderão modificá-lo, melhorá-lo e adequá-lo à realidade local.

\section{Referências Bibliográficas}

ALENCAR, E.; GOMES, M. A. O. 2001. Ecoturismo e planejamento social. Textos acadêmicos. Universidade Federal de Lavras - UFLA.

BACKMAN, G. 2001. Environmental evaluation: perception and public policy. Monterey, CA: Brooks/Cole Publishing Company.

BALCAR, M. J. O.; PEARCE, D. G. 1996. Heritage tourism on the West Coast of New Zealand. Tourism Management, 17 (3), p. 203-212.

BANNON, J. J. 1976. Leisure resources: its comprehensive planning. New Jersey.

BETTELINI, J. M.; CANTIANI, F.; MARIOTTA, H. 2000. Tools for sustainability analysis in planning and managing tourism and recreation in the destination. In: HALL,C. M.; LEW, A.A. (Eds.) Sustainable tourism. A geographical perspective. New York.

BISSIX, G. 2000. A forest recreation decision support system: the woodlot outdoor recreation opportunity spectrum (woROS). In: Leisure. Journal of the Canadian Association for Leisure Studies. 24 (3-4), p. 299-320.

BOYD, S. W.; BUTLER, R. W. 1996. Managing ecotourism: an opportunity spectrum approach. Tourism Management, 17 (8), p. 557-566.

CHIN, C. L. M.; MOORE, S. A.; WALLINGTON, J.; DOWLING, R. K. 2000. Ecoturism in Bako National Park, Borneo: visitor's perspectives on environmental impacts and their management. Journal of Sustainable Tourism, 8 (1), p. 20-35.

CLARK, R. N.; STANKEY, G. H. 1979. The recreation opportunity spectrum: a framework for planning, management and research. Department of Agriculture. Forest Service.

FERNIE, K. J. 1993. 115 f. Ecotourism: a conceptual framework from the ecotourist perspective unpublished. MSc thesis, Department of Forestry, University of Toronto, Toronto.

GALLOWAY, G. 2002. Psychographic segmentation of park visitor markets: evidence for the utility of sensation seeking. Tourism Management, 23, p. 581-596. 
GOBSTER, P. 1998. Explanation for minority "underparticipation" in outdoor recreation: a look at Golf. Journal of Park and Recreation Administration, 16 (1), p. 15-25.

GUNN, C. 1993. Tourism planning: basics, concepts, cases. New York: Taylor \& Francis.

INSKEEP, E. 1991. Tourism planning. An integrated and sustainable development approach. Canada.

LOK, F. J. 2000. Visitor planning and management in parks and protected areas. In: DEADEN, P.; ROLLINS, R. (Eds.). Parks and protected areas in Canada: Planning and management. Toronto, ON: Oxford University Press.

MORGAN, D.; LOK, L. 2000. Assessment of a Comfort indicator for natural tourist attractions: the case of visitors to Hanging Rock, Victoria. Journal of Sustainable Tourism, 8 (5), p. 393-409.

MORIN, S. L.; MOORE, S. A.; SCHIMIDT, W. 1997. Defining indicators and standards for recreation impacts in Nuyts Wilderness, Walpole-Nornalup Park, Western Australia. CALMScience, 2 (3), p. 247-266.

MURPHY, P.E. 1985. Tourism: a community approach. London: Methuen.

OBUA, J.; HARDING, D. M. 1996. Visitor characteristics and attitudes towards Kibale National Park, Uganda. Tourism Management, 17 (7), p. 495-505.

RYAN, C.; STERLING, L. 2001. Visitors to Litchfield National Park, Australia: a typology based on behaviours. Journal of Sustainable Tourism, 9 (1), p. 61-75.

SALEH, F.; KARWACKI, J. 1996. Revisiting the ecotourist: the case of Grasslands National Park. Journal of Sustainable Tourism, 4 (2), p. 61-80.

SHETTY, S. 1991. Development Projects in Assessment Framework, Occasional Paper series, Society for Participatory Research in Asia.

SPON, F. N. 1983. Recreation site survey. Methods and techniques for conducting visitor surveys. Tourism and Recreation Research Unit. Edinburgh.

STRAUSS, A.; CORBIN, J. 1990. Basics of qualitative research: grounded theory procedures and techniques. London: Sage Publications.

TORKILDSEN, H. 1986. Basics of qualitative research: grounded theory procedures and techniques. London: Sage Publications.

VEAL, A. J. 1997. Meeting planners' use and evaluation of convention and visitor bureaus. Tourism Management, 22 (6), p. 599-606.

WEAVER, D. B.; LAWTON, L. J. 2001. Resident perceptions in the urban-rural fringe. Annals of Tourism Research, (28) 2, p. 439-458.

Recebido em 21/012003.

Aprovado em 18/06/2003. 